ENSAYO

\title{
CONOCIMIENTO DEL OTRO
}

\section{Carla Cordua}

Don Quijote y Sancho, de la misma aldea, sólo llegan a conocerse personalmente haciendo vida en común. Compartiéndolo todo, acaban intimando. En este artículo se sugiere que el conocimiento mutuo se convierte en reconocimiento de los respectivos méritos, pero no impide la crítica, el engaño o el abandono del otro. Por el contrario, la intimidad es la condición de que Sancho sepa cómo mentirle a su amo y manipularlo y de que éste pueda abandonar a Sancho sin escrúpulos y contra la voluntad del escudero, después de haberlo sacado de su vida aldeana, llenándole la cabeza de fantasías.

Carla Cordua. Doctora en filosofía por la Universidad Complutense de Madrid. Miembro de número de la Academia Chilena de la Lengua. Profesora titular de la Universidad de Chile y directora de su Revista de Filosofia. Profesora emérita de la Universidad de Puerto Rico. Autora, entre otras publicaciones, de El mundo ético: Ensayos sobre la esfera del hombre en la filosofia de Hegel (Barcelona, 1989), Wittgenstein: Reorientación de la filosofia (Santiago, 1997), Luces oblicuas (Santiago, 1997), Filosofía a destiempo (Santiago, 1999), Nativos de este mundo (Santiago, 2004) y Verdad y sentido en La crisis de Husserl (Santiago, 2004).

Estudios Públicos, 100 (primavera 2005). 


\section{Irse conociendo}

L

a narración de la nueva vida que elige don Quijote al comienzo de la novela de Cervantes empieza con la primera salida de su casa. En ésta se trata todavía de una empresa solitaria. Después de ella, cuando el hidalgo prepara la segunda salida, decide hacerse acompañar por un vecino, Sancho Panza, a quien le pide que sea su escudero. La de escudero es una función sacada de la fantasía novelesca de don Quijote que, inicialmente al menos, no significa nada para Sancho, que no sabe leer. El futuro acompañante de don Quijote es descrito así: "Un labrador vecino suyo, hombre de bien —si es que este título se puede dar al que es pobre-, pero de muy poca sal en la mollera" (I, VII). Don Quijote ha de vencer la resistencia que Sancho opone a la inusual solicitación, de la que éste no sabe sino que se la hace su vecino, el hidalgo. El futuro caballero lo convencerá con promesas, y pintándole las oportunidades de ganancias fáciles y rápidas que ofrece la vida caballeresca a quienes la practican. Sancho, a quien no le falta sal en la mollera, es, sin embargo, un lugareño de estrechos horizontes, que cree fácilmente en la versión de las caballerías que le pinta su vecino; la diferencia de posición social, de fortuna, de educación, también favorecen que él acepte servir a su vecino. Parece cosa tan natural. En cualquier caso, es notable que acuerden salir de sorpresa y a escondidas y, en este sentido, se ve que no las tienen todas consigo. Por precaución deciden no despedirse de sus respectivas familias.

En los capítulos iniciales el narrador insiste constantemente en los contrastes polares que separan a don Quijote y Sancho. Algunas de estas diferencias reflejan la relación de amo y sirviente, o, en el lenguaje del señor, de caballero y escudero. Don Quijote tutea a Sancho mientras éste lo trata de 'vuestra merced'. Los animales que cabalgan son, uno noble, el otro, una bestia de carga más que una cabalgadura presentable. Don Quijote se resigna a la indignidad de que Sancho monte un asno pensando en que el primer caballero al que derrote será despojado de su caballo para montar en él a su escudero. Todas las costumbres de los miembros de la pareja son distintas, y también sus modos de hablar, de pensar y de reaccionar ante situaciones nuevas. Sancho piensa a menudo en comer y en procurarse algunas comodidades para dormir mientras que don Quijote vela de noche y come sólo ocasionalmente, orgulloso de sus triunfos sobre las necesidades naturales. "Hágote saber, Sancho, que es honra de los caballeros andantes no comer en un mes y, ya que coman, sea de aquello que hallaren más a mano" (I, x). Un contraste flagrante se pone en evidencia pronto entre lo que perciben uno y el otro. Don Quijote elude hacerse cargo de las cosas como son, en 
su esfuerzo por ajustarse a los ideales y las reglas de la caballería andante; Sancho es insobornablemente realista y prosaico, ve lo que hay allí para ver. Uno habla y pronuncia discursos literatosos, el otro desaprueba del mucho hablar en vez de descansar de los accidentes y penas del día (I, XII).

Estos dos personajes polarmente opuestos deberán recorrer distancias y vencer extrañezas, superar las primeras reacciones, antes de comenzar a entenderse mutuamente. No se han frecuentado en sus existencias anteriores de vecinos desiguales. Ahora, a pesar de no conocerse suficientemente, tienen que compartirlo todo, de día y de noche, en las buenas y en las malas. Diversos obstáculos se oponen inicialmente a que crezca entre ellos la comprensión mutua y el conocimiento del otro. Sólo Sancho parece interesado en su amo y en lo que se propone. El caballero, en cambio, da por descontado que sabe de antemano lo que son las cosas y las personas. En la medida en que algunos aspectos de las situaciones nuevas consiguen colarse a través del espeso velo literario que le nubla la vista, el caballero tiende a molestarse fácilmente. Se irrita porque Sancho pronuncia mal algunas palabras cultas o porque confunde unos vocablos con otros. Lo enoja la ignorancia del escudero y lo corrige con impaciencia constantemente. Además, al darle instrucciones sobre la conducta debida de un escudero, se refiere abiertamente a la ignorancia, la falta de distinción y de rango social de Sancho.

"Advierte que, aunque me veas en los mayores peligros del mundo, no has de poner mano a tu espada para defenderme, si ya no vieres que los que me ofenden es canalla y gente baja, que en tal caso bien puedes ayudarme; pero si fueren caballeros, en ninguna manera te es lícito ni concedido por las leyes de caballería que me ayudes, hasta que seas armado caballero" (I, VIII). También lo hace callar cuando Sancho opina sobre lo que puede ocurrirles después del combate con miembros de la Santa Hermandad. "Calla, dijo don Quijote, ¿y dónde has visto tú, o leído jamás, que caballero andante haya sido puesto ante la justicia, por más homicidios que haya cometido?" (I, x). "No estás cursado en esto de las aventuras" (I, VIII).

Sancho no se ofende; tiene bien asimilada su posición social y don Quijote no hace más que actuar de acuerdo a las convenciones establecidas. Por lo demás, el amo lo trata bien verbalmente, llamándolo 'Sancho amigo', 'hermano Sancho'. Así, a ambos les parece que todo está en regla. A propósito de la reiteración de la promesa de convertir a Sancho en gobernador, se dice: "Agradecióselo mucho Sancho, y, besándole otra vez la mano y la falda de la loriga, le ayudó a subir sobre Rocinante;" (I, x). En el encuentro con los cabreros don Quijote enuncia otra de sus fantasías caballerescas, la de la igualación de amo y sirviente. Viendo a Sancho de pie para 
servirle una copa, le dice: "Quiero que aquí a mi lado y en compañía de esta buena gente te sientes, y que seas una cosa conmigo, que soy tu amo y natural señor; que comas en mi plato y bebas por donde yo bebiere; porque de la caballería andante se puede decir lo mesmo que del amor se dice: que todas las cosas iguala" (I, XI). En el nombre de la propia comodidad rechaza Sancho el ofrecimiento de compartir comida y bebida con nadie. Ha dejado de aceptar algunas de las fantasías de su amo y ésta es de las menos creíbles.

Entretanto, y por un lado difícil de sospechar para los protagonistas, la vida que comparten da lugar al desarrollo de otra gran diferencia entre don Quijote y Sancho. Durante las batallas y refriegas de don Quijote, el precavido y algo cobarde Sancho se mantiene a distancia, pero observando el curso de los acontecimientos. No sólo presta atención a las palabras de su señor sino que todo el tiempo Sancho es un observador intenso, detallista y penetrante de la situación presente y de la conducta de don Quijote en ella. En particular, cuando don Quijote anuncia que luchará con uno de sus supuestos enemigos, el cauteloso sirviente observa la cosa desde un lado. Terminada la refriega, recoge al amo del suelo y, de ser posible, lo sacude y pone de pie. Como observador, Sancho es muy eficaz, a juzgar por los comentarios que hace sobre lo que ha visto. Cuando don Quijote le pide que observe las locuras de que es capaz para que pueda contárselas a Dulcinea, Sancho le dice, razonablemente: "Pues ¿qué más tengo de ver que lo que he visto?" (I, XXv).

En otra ocasión, el narrador describe la situación como sigue: "Tal fue el golpe primero, y tal el segundo, que le fue forzoso al pobre caballero dar consigo del caballo abajo. Llegáronse a él los pastores y creyeron que le habían muerto... Estábase todo este tiempo Sancho sobre la cuesta, mirando las locuras que su amo hacía, y arrancábase las barbas, maldiciendo la hora y el punto en que la fortuna se lo había dado a conocer. Viéndole, pues, caído en el suelo, y que ya los pastores se habían ido, bajó de la cuesta y llegóse a él, y hallóle de muy mal arte, aunque no había perdido el sentido, y díjole: ¿No le decía yo, señor don Quijote, que se volviese, que los que iba a acometer no eran ejércitos, sino manadas de carneros?" (I, XVIII).

En su paciente capacidad de observador eficaz, Sancho difiere de don Quijote. No es sólo que el criado sea más realista que su fantasioso señor, sino, sobre todo, que presta atención, piensa circunspectamente y respeta lo que ve. Don Quijote, en cambio, es distraído y tiene la cabeza llena de anticipaciones y prejuicios sobre lo que las cosas deberían ser. Además, comete varios de los errores paradigmáticos del amo: cree haberse 
convertido en propietario del sirviente, y supone que esta situación lo faculta para valerse en adelante de su sirviente sin mayores trámites e investigaciones. Dice don Quijote a Sancho: "Los cielos te den gracia para que caigas en la cuenta y en la obligación que te corre de ayudar a mi señora, que lo es tuya, pues tú eres mío" (II, LXVII). Pero Sancho sabe que las cosas no son tan simples. En una ocasión anterior ya le ha advertido al amo cuál es la relación que tiene consigo mismo: "Ni quito rey, ni pongo rey, sino ayúdome a mí, que soy mi señor" (II, LX). A los pretendidos propietarios de quienes los sirven no se les ocurre nunca que las personas son, literalmente, inapropiables por la simple razón de que ya tienen dueño y señor, esto es, ya se tienen a sí mismos con quienes consultar acerca de cómo son las cosas. Don Quijote, en consecuencia, no observa a Sancho y, por eso, llega a saber menos sobre él que Sancho sobre don Quijote. Pero como es amo generoso está dispuesto a reconocer los méritos del sirviente y, en momentos de entusiasmo, lo exaltará de la siguiente manera: "Sancho Panza, mi escudero, que es el mejor hombre del mundo... es uno de los mejores escuderos que caballero andante ha tenido" (I, L; cf. I, XLIV).

Pero es Sancho quien bautiza a su señor con su segundo nombre y lo hace después de haberlo observado por algún tiempo. El narrador cuenta: "Díjole también Sancho: Si acaso quisieren saber esos señores quién ha sido el valeroso que tales los puso, diráles vuestra merced que es el famoso don Quijote de la Mancha, que por otro nombre se llama el Caballero de la Triste Figura... Con esto, se fue el bachiller; y don Quijote preguntó a Sancho que qué le había movido a llamarle el Caballero de la Triste Figura, más entonces que nunca... Yo se lo diré — respondió Sancho-; porque le he estado mirando un rato a la luz de aquella hacha que lleva aquel malandante, y verdaderamente tiene vuestra merced la más mala figura, de poco acá, que jamás he visto; y débelo de haber causado, o ya el cansancio deste combate, o ya la falta de las muelas y dientes" (I, XIX). De pronto, ya madura su convicción, Sancho formula el juicio, basado sobre la observación, que le merecen don Quijote y su empresa: "A lo cual respondió Sancho: Vive Dios, señor Caballero de la Triste Figura, que no puedo sufrir ni llevar en paciencia algunas cosas que vuestra merced dice, y que por ellas vengo a imaginar que todo cuanto me dice de caballerías y de alcanzar reinos e imperios, de dar ínsulas y de hacer otras mercedes y grandezas, como es uso de caballeros andantes, que todo debe de ser cosa de viento y mentira, y todo pastraña, o patraña, o como lo llamáremos. Porque quien oyere decir a vuestra merced que una bacía de barbero es el yelmo de Mambrino, y que no salga de este error en más de cuatro días, ¿qué ha de pensar, sino que quien tal dice y afirma debe de tener güero el juicio?” (I, xxv). 


\section{El reconocimiento}

Don Quijote, más intelectual que observador, al ir intimando progresivamente con Sancho, va sacando conclusiones generales sobre su interlocutor y sirviente y son estas generalidades las que dominan su pensamiento acerca del escudero. Muchas de sus convicciones están ligadas a las impaciencias del amo frente a ciertos rasgos repetitivos de la conducta de Sancho: no sólo le molestan sus modos de hablar y en particular las deformaciones de voces que el analfabeto aprende solo de oídas y no ha visto nunca escritas. "Erutar, Sancho, quiere decir regoldar, y éste es uno de los más torpes vocablos que tiene la lengua castellana, aunque es muy significativo" (II, XLIII). También los refranes de Sancho, que don Quijote a menudo encuentra mal encajados en el tema que en el momento los ocupa, irritan al caballero y le provocan los reproches que dirige a Sancho. En una escena de Sierra Morena se desarrolla el siguiente diálogo entre Sancho y don Quijote:

"Ni yo lo digo ni lo pienso — respondió Sancho-; allá se lo hayan; con su pan se lo coman. Si fueron amancebados, o no, a Dios habrán dado la cuenta. De mis viñas vengo, no sé nada; no soy amigo de saber vidas ajenas; que el que compra y miente, en su bolsa lo siente. Cuanto más, que desnudo nací, desnudo me hallo: ni pierdo ni gano; mas que lo fuesen, ¿qué me va a mí? Y muchos piensan que hay tocinos y no hay estacas. Mas, ¿quién puede poner puertas al campo? Cuanto más, que de Dios dijeron.

¡Válame Dios — dijo don Quijote_, y qué de necedades vas, Sancho, ensartando! ¿Qué va de lo que tratamos a los refranes que enhilas? Por tu vida, Sancho, que calles, y de aquí adelante, entremétete en espolear a tu asno, y deja de hacello en lo que no te importa. Y entiende con todos tus cinco sentidos que todo cuanto yo he hecho, hago e hiciere, va muy puesto en razón y muy conforme a las reglas de caballería, que las sé mejor que cuantos caballeros las profesaron en el mundo" (I, XXV; cf. II, LXVII y LXVIII).

Inicialmente don Quijote no hace ningún esfuerzo por comprender el papel que los refranes y frases hechas de Sancho, esas cápsulas de la sabiduría popular, desempeñan en la vida mental del escudero. “¡Oh, maldito seas de Dios, Sancho! dijo a esta sazón don Quijote. ¡Sesenta mil satanases te lleven a ti y a tus refranes! Una hora ha que los estás ensartando y dándome con cada uno tragos de tormento. Yo te aseguro que estos refranes te han de llevar un día a la horca; por ellos te han de quitar el gobierno tus vasallos, o ha de haber entre ellos comunidades. Dime, ¿dónde los hallas, ignorante, o cómo los aplicas, mentecato, que para decir yo uno y aplicarle bien, sudo y trabajo como si cavase? 
Por Dios, señor nuestro amo — replicó Sancho-, que vuesa merced se queja de bien pocas cosas. ¿A qué diablos se pudre de que yo me sirva de mi hacienda, que ninguna otra tengo, ni otro caudal alguno, sino refranes y más refranes? Y ahora se me ofrecen cuatro que venían aquí pintiparados, o como peras en tabaque, pero no los diré, porque al buen callar llaman Sancho" (II, XLIII).

Sólo después de expresar su enojo procede don Quijote a darle un reconocimiento a Sancho como sabedor de refranes. Cuando el conocimiento mutuo ya está bien establecido, y sin abandonar las convicciones previas de carácter negativo acerca del conocido, da muestras don Quijote de apreciar la sabiduría del tesoro guardado en forma de refranes en la mente de Sancho. Llega, incluso, a imitarlo, como se lo hace ver Sancho, diciéndole: "No soy yo ahora el que ensarta refranes; que también a vuestra merced se le caen de la boca de dos en dos mejor que a mí" (II, LXVIII). Este es el momento del reconocimiento en el sentido del saber acerca de otro que incluye una apreciación de su mérito o virtudes. Aconsejándolo sobre su gobernación, le dice: "También, Sancho, no has de mezclar en tus pláticas la muchedumbre de refranes que sueles; que puesto que los refranes son sentencias breves, muchas veces los traes tan por los cabellos, que más parecen disparates que sentencias.

Eso Dios lo puede remediar — respondió Sancho—; porque sé más refranes que un libro, y viénenseme tantos juntos a la boca cuando hablo, que riñen, por salir, unos con otros; . . . Mas yo tendré cuenta de aquí adelante de decir los que convengan a la gravedad de mi cargo; . . ¡ ¡Eso sí, Sancho! — dijo don Quijote—. ¡Encaja, ensarta, enhila refranes; que nadie te va a la mano! . . . Mira, Sancho, no te digo yo que parece mal un refrán traído a propósito; pero cargar y ensartar refranes a troche moche hace la plática desmayada y baja... Y con todo eso querría saber qué cuatro refranes te ocurrían ahora a la memoria que venían aquí a propósito, que yo ando recorriendo la mía, que la tengo buena, y ninguno se me ofrece" (II, XLIII).

Pero como a pesar de sus frecuentes enojos y críticas, don Quijote es un amo generoso, está dispuesto a reconocer los grandes méritos del sirviente, el valor de sus servicios; de modo que, en momentos de entusiasmo, lo exaltará de la siguiente manera: "Sancho Panza, mi escudero, que es el mejor hombre del mundo... es uno de los mejores escuderos que caballero andante ha tenido" (I, L; cf. I, XLIV). El reconocimiento llega a ser, en este caso, mutuo. También poco a poco y sin abandonar su convicción de que don Quijote es loco, Sancho encuentra más de una oportunidad de manifes- 
tar el cariño y admiración que tiene por su señor. Y también su gratitud por la educación que de su compañía ha recibido.

"Algo se me ha de pegar de la discreción de vuestra merced — respondió Sancho-; que las tierras que de suyo son estériles y secas, estercolándolas y cultivándolas vienen a dar buenos frutos: quiero decir que la conversación de vuestra merced ha sido el estiércol que sobre la estéril tierra de mi seco ingenio ha caído; la cultivación, el tiempo que ha que le sirvo y comunico; y con esto espero de dar frutos de mí que sean de bendición, tales, que no desdigan ni deslicen de los senderos de la buena crianza que vuesa merced ha hecho en el agostado entendimiento mío" (II, XII).

Cuando Sancho platica con el escudero del Caballero del Bosque saca a relucir su matizada opinión sobre su amo y reconoce que lo quiere mucho tal cual es. Primero llama 'tontos' a don Quijote y al del Bosque. El otro escudero contesta que el suyo es "tonto pero valiente, y más bellaco que tonto y que valiente". Sancho protesta. "Eso no es el mío, digo, que no tiene nada de bellaco; antes tiene una alma como un cántaro: no sabe hacer mal a nadie, sino bien a todos, ni tiene malicia alguna: un niño le hará entender que es de noche en la mitad del día, y por esta sencillez le quiero como a las telas de mi corazón, y no me amaño a dejarle, por más disparates que haga" (II, XIII).

$\mathrm{Al}$ comienzo de la segunda parte de la novela la intimidad entre los compañeros de aventura está bien establecida y es la base de secreteos y acuerdos entre don Quijote y Sancho a espaldas de otros personajes. El segundo capítulo de esta parte narra una ocasión en que el cura y el barbero ventilan su opinión desfavorable hacia las salidas del par de aventureros. Don Quijote se encierra en su aposento con Sancho para no ser escuchado por nadie con el fin de acordar en secreto lo que se puede decir y lo que hay que callar en el pueblo y en la casa acerca de la vida que hacían en común. "Mucho me pesa, Sancho, que hayas dicho y digas que yo fui el que te saqué de tus casillas, sabiendo que yo no me quedé en mis casas; juntos salimos, juntos fuimos y juntos peregrinamos; una misma fortuna y una misma suerte ha corrido por los dos" (II, II).

\section{Intimidad y engaño}

Como consecuencia del mejor y progresivo conocimiento mutuo se establecen relaciones de intimidad y aprecio mutuo entre don Quijote y Sancho. Los compañeros de aventuras se manifiestan cariño y reconoci- 
miento y, ocasionalmente, también se critican con franqueza uno al otro. La colaboración entre ellos se mantiene constante y es muy solícita hasta el final de la narración, cuando es Sancho quien defiende la vida caballeresca que don Quijote quiere abandonar. De la compenetración progresiva de uno con el otro surge el compañerismo de quienes lo comparten todo. La capacidad de prever la conducta y reacciones del otro se intensifica y profundiza en ambos debido al conocimiento adquirido. Don Quijote, en su candidez, no sólo reconoce las virtudes de Sancho sino que confía en él, a menudo más de la cuenta. No obstante, a veces cree necesario exigirle lealtad, repitiéndole que debe decirle la verdad entera, como si sospechara que no lo hace siempre. "Finalmente quiero, Sancho, me digas lo que acerca desto ha llegado a tus oídos: y esto me has de decir sin añadir al bien ni quitar al mal cosa alguna; que de los vasallos leales es decir la verdad a sus señores en su ser y figura propia, sin que la adulación la acreciente o otro vano respeto la disminuya; ...Eso haré yo de muy buena gana, señor mío — respondió Sancho" (II, II).

Pero Sancho, valiéndose de su conocimiento y de su capacidad de anticiparse a las reacciones de don Quijote, lo engañará en repetidas ocasiones. El engañador se vale en ellas, para equivocar al otro a su conveniencia, de los resortes conocidos de la conducta del amo, aquellos de los que sabe que entrarán en acción en situaciones para Sancho previsibles. Cervantes muestra instructivamente cómo desde el centro mismo del conocimiento del otro y de la intimidad con él, surge la posibilidad de engañarlo. Los elementos de picardía en la personalidad de Sancho, y también su conciencia de la disparidad entre las situaciones que afectan al señor y las que alcanzan al criado, lo tientan a aprovechar más de una vez la posibilidad de engañarlo. Engañar a un desconocido es más difícil que a un íntimo pues no se dispone sino de representaciones generales, que bien pueden resultar inadecuadas en el caso específico y conducir al fracaso de la mala intención. De manera que la deslealtad y las mentiras que la acompañan, florece a menudo exitosamente allí donde las vidas de victimarios y víctimas están estrechamente ligadas entre sí y dan pie a la confianza infundada de la víctima.

Entre los engaños más notables y mañosamente urdidos por Sancho se encuentra la treta de amarrar, por miedo de la ruidosa noche, las patas de Rocinante para que el caballero no intente acción alguna, dejándolo solo. Don Quijote niega que haya circunstancias que le puedan impedir hacer lo que debe como andante caballero. "Viendo, pues, Sancho la última resolución de su amo, y cuán poco valían con él sus lágrimas, consejos y ruegos, determinó de aprovecharse de su industria y hacerle esperar hasta el día 
siguiente; y así, cuando apretaba las cinchas al caballo, bonitamente y sin ser sentido, ató con el cabestro de su asno ambos pies a Rocinante, de manera que cuando don Quijote se quiso partir, no pudo, porque el caballo no se podía mover sino a saltos. Viendo Sancho Panza el buen suceso de su embuste, dijo: Ea, señor, que el cielo, conmovido de mis lágrimas y plegarias, ha ordenado que no se pueda mover Rocinante; y si vos queréis porfiar, y espolear, y dalle, será enojar a la Fortuna, y dar coces, como dicen, contra el aguijón" (I, xx).

La habilidad para fabricar un argumento que, explicando la inmovilidad del caballo, resulte previsiblemente aceptable para don Quijote por la intervención en él del cielo y de la Fortuna, es característica del Sancho que ya conoce a su amo. Sabemos que Sancho no cree en brujerías ni en hechizos (cf. I, XLVI, XLVII, XLVIII y XLIX); sin embargo, no vacila en cubrir sus fechorías y trampas aduciendo encantamientos debidos a las acciones de brujos, nigromantes y encantadores de todo tipo. Es que la industria de Sancho incluye a los agentes fantásticos de las novelas de caballería que ha oído citar a su señor y en las que éste deposita toda su fe. "Andaba Sancho buscando la cabeza del gigante por todo el suelo, y como no la hallaba, dijo: 'Ya yo sé que todo lo desta casa es encantamiento"' (I, Xxv). El capítulo x de la segunda parte de la novela lleva como título Donde se cuenta la industria que Sancho tuvo para encantar a la señora Dulcinea, y de otros sucesos tan ridículos como verdaderos. Más adelante, el escudero dice: "Yo no creo que mi señor miente, respondió Sancho. —Si no, ¿qué crees?-, le preguntó don Quijote. Creo, respondió Sancho, que aquel Merlín o aquellos encantadores que encantaron a toda la chusma que vuestra merced dice que ha visto y comunicado allá bajo, le encajaron en el magín o la memoria toda esa máquina que nos ha contado, y todo aquello que por contar le queda" (II, XXIII).

La explicación de su fingida embajada a Dulcinea (I, Xxv y xxx) desde la Sierra Morena, muestra tanto la habilidad del escudero para mentir como varios aspectos de su prosaica imaginación y algunos tristes restos de su fidelidad inicial a su señor. Llegados al Toboso "rabiaba Sancho por sacar a su amo del pueblo, porque no averiguase la mentira de la respuesta que de parte de Dulcinea le había llevado" (II, x). Don Quijote lo envía de nuevo donde Dulcinea para que ella se deje ver de su enamorado. El irónico narrador comenta: "Encargóse Sancho de hacerlo así como se le mandaba, y de traer tan buena respuesta como le trujo la vez primera". Aceptando el encargo para Dulcinea dice Sancho a don Quijote: "Yo iré y volveré presto ... Si esta noche no hallamos los palacios o alcázares de mi señora, agora que es de día los pienso hallar, cuando menos los piense, y hallados, déjenme a mí 
con ella". Confiando en que don Quijote confunde todo lo que ve y lo toma por otra cosa, aprovecha la cercanía de tres labradoras para volver y decirle al caballero que ha venido a verlo la mismísima Dulcinea acompañada por dos doncellas.

"De ese modo, replicó don Quijote, buenas nuevas traes. - Tan buenas, respondió Sancho, que no tiene más que hacer vuesa merced sino picar a Rocinante y salir a lo raso a ver a la señora Dulcinea del Toboso, que con otras dos doncellas suyas viene a ver a vuesa merced. — ¡Santo Dios! ¿Qué es lo que dices, Sancho amigo?, dijo don Quijote. Mira no me engañes, ni quieras con falsas alegrías alegrar mis verdaderas tristezas. — ¿Qué sacaría yo de engañar a vuesa merced, respondió Sancho, y más estando tan cerca de descubrir mi verdad? Pique, señor, y venga, y verá venir a la princesa, nuestra ama, vestida y adornada, en fin, como quien ella es. Sus doncellas y ella todas son una ascua de oro, todas mazorcas de perlas, todas son diamantes, todas rubíes, todas telas de brocado de más de diez altos; los cabellos, sueltos por las espaldas, que son otros tantos rayos del sol que andan jugando con el viento; y, sobre todo, vienen a caballo sobre tres cananeas remendadas, que no hay más que ver. - Hacaneas querrás decir, Sancho. -Poca diferencia hay, respondió Sancho, de cananeas a hacaneas; pero, vengan sobre lo que vinieren, ellas vienen las más galanas señoras que se puedan desear, especialmente la princesa Dulcinea, mi señora, que pasma los sentidos".

Esta vez don Quijote ve lo que hay allí para ver y queda desconcertado frente a las aldeanas; pero no tarda en interpretar lo que ve como Sancho había previsto. "Sancho, ¿qué te parece cuán mal quisto soy de encantadores? . . . - iOh canalla!, gritó a esta sazón Sancho. ¡Oh encantadores aciagos y mal intencionados!" (II, x). "Harto tenía que hacer el socarrón de Sancho en disimular la risa, oyendo las sandeces de su amo, tan delicadamente engañado" (Ibid.).

La empresa de engañar con éxito a alguien cercano cuesta atención y esfuerzo. Tal como mentir bien, ella no resulta cosa fácil de llevar a cabo: hay que saber mantenerse cerca de lo verosímil, sostener la coherencia de la intriga, adaptarla a las reacciones del engañado y conservarse alerta a posibles sospechas, dudas, objeciones y complicaciones de la situación. El mentiroso ha de dedicarse a su víctima, cultivar la intimidad con ella y no permitir que influencias destructivas provenientes de otras fuentes de información desbaraten la maquinación. En este sentido de la dedicación al otro que reclaman, el engaño y la mentira pueden contribuir a estrechar los lazos de la amistad y el compañerismo. Otros desarrollos de la intimidad compartida por dos personas, en cambio, pueden producir efectos contrarios. En el 
caso de don Quijote y Sancho a lo largo de la novela, vemos que el amo comienza a desinteresarse paulatinamente de la actividad caballeresca que lo ha sacado, a él y a su escudero, por tercera vez, de su pueblo y de sus casas. A pesar de la intimidad que los liga, don Quijote necesita cada vez menos a Sancho. A medida que aumentan las visitas y las estadías pacíficas en diversas casas y localidades, disminuye la vida aventurera al acaso; los personajes se entregan a una sociabilidad que bien puede prescindir de escudero. La pareja que hacen don Quijote y Sancho se separa ocasionalmente y se vuelve a encontrar; ambos emprenden asuntos diversos y la estrechez de su relación anterior es reemplazada por conversaciones en que se cuentan mutuamente los principales sucesos vividos independientemente.

\section{Intimidad y deserción}

Al comenzar la segunda parte de la novela, don Quijote y Sancho son sólo hasta cierto punto los mismos que conoce el lector de la primera parte. A poco andar, la parte final del libro muestra que don Quijote es, en vez del caballero ingenuo que salió de su casa en busca de aventuras, en medida creciente, el personaje literario de la primera parte, que entretanto ha ganado fama y se complace en conversarla con sus supuestos admiradores. El caballero se irá tornando tema de salón y dócil objeto de la malicia de otros a medida que pasa de tertulia en tertulia. Y Sancho, lleno de asombro al comienzo, dispuesto a aprender sobre caballerías y funciones escuderiles, discute ahora estos asuntos con sus colegas (II, XIII) como un fogueado profesional. Gastada la novedad todo se habrá transformado. Pero al salir de la casa por tercera vez todavía no se hacen patentes sino los primeros signos de la nueva situación.

Todavía entre los suyos, el caballero es interrogado sobre su vida de aventuras por la sobrina y el ama, por el cura y el barbero del pueblo, por Sansón Carrasco. Explica las caballerías tal como ha estado haciendo antes; al parecer, su entusiasmo y convicción no han disminuido. Declara la continuidad de su vocación: "Caballero andante he de morir" (II, I). Sancho, por su parte, reclama compensaciones y se queja de que no se le han cumplido las promesas hechas. Don Quijote contesta: "Aún hay sol en las bardas; y mientras más fuere entrando en edad Sancho, con la esperiencia que dan los años, estará más idóneo y más hábil para ser gobernador que no está agora" (II, III). A pesar de que este es el tono acostumbrado que el lector de la primera parte reconoce, la segunda de la novela en conjunto difiere profun- 
damente de la primera. Sus numerosas novedades se irán manifestando paulatinamente.

La acción se traslada al palacio de los duques; el duque y la duquesa, su corte e incluso algunos de sus sirvientes, han leído o escuchado la primera parte del libro. Don Quijote es célebre y celebrado precisamente allí donde todos convienen en burlarse de él. Se cuentan historias de amor, las desgracias de la cortesana Altisidora; se organizan fiestas y alegres farsas para divertirse a la manera aristocrática; se planea el desencantamiento de Dulcinea. Pronto el montaje burlesco alcanza a Sancho, que es embarcado por los duques en su gran experiencia política. La fantasía lúdica de los duques y sus cortesanos trata a Sancho como él solía hacer con su amo: fingiendo creer que un escudero puede conquistar una gobernación y que las ínsulas se regalan a cambio de sus servicios a quienes les han sido prometidas. Aconsejado con toda seriedad por don Quijote, Sancho acabará acomodándose en silencio a su desengaño, uno de los mayores sufridos hasta entonces. Lo aguardan otros más graves.

Desde la aldea de don Quijote provienen otros organizadores de farsas que se suman a la actividad teatral y a las burlas de salón que dominan en la segunda parte de la novela. Hay allí también, por cierto, festejos legítimos, como las bodas de Camacho el rico, encuentros con titereros, tertulias con don Diego de Miranda y otros. Además, don Quijote sueña y tiene visiones, y aún les da crédito (II, XXIII). Pero lo que disminuye rápidamente son las verdaderas aventuras, esos sucesos dominados por el azar de los encuentros y de los caminos; ellas cederán el lugar a las farsas y pláticas montadas para el personaje literario de la primera parte de la novela. El héroe ha caído en manos de los artimañosos burladores y de los no solicitados protectores de Alonso Quijano. Que ya no le ocurra nada que surge espontáneamente de la suerte, buena o mala, viene a ser el precio de la fama, el terrible precio que, según Cervantes lo ve, pagará don Quijote por el éxito de su ambición de conquistar un nombre. Sin lograr ninguno de sus otros propósitos, parece que el caballero fracasado goza de fama gracias al éxito del libro que cuenta sus andanzas. Don Quijote consigue otra cosa que la que quería: lo que le llega de las farsas de los demás es no sólo diferente de la aventura sino lo contrario de ella. Pues su fama resulta ser un espejismo tan engañoso como las anacrónicas caballerías perseguidas por don Quijote.

Con la transformación de las circunstancias llega también a su última etapa la relación de don Quijote y Sancho. La intimidad que ha crecido entre ellos toma su forma terminal. Esta forma se establece debido, principalmente, a que don Quijote, más melancólico que entusiasta, ya piensa a menudo 
en la muerte (II, XII). Le dice a Sancho: "Come, Sancho amigo, sustenta la vida, que más que a mí te importa, y déjame morir a mí a manos de mis pensamientos y a fuerzas de mis desgracias" (II, LIX). El caballero se aleja de la vida que ha venido llevando, para terminar abandonándola $\mathrm{y}$, con ella, también a Sancho. El escudero siente oscuramente como crece la indiferencia del amo hacia él. Protesta en ocasiones, mientras don Quijote no ha declarado aún su decisión final de dejar la vida caballeresca que han llevado juntos. Dice, por ejemplo: “A la fe, señor nuestro amo, el mal ajeno de pelo cuelga, y cada día voy descubriendo tierra de lo poco que puedo esperar de la compañía que con vuestra merced tengo; porque si esta vez me ha dejado apalear, otra y otras ciento volveremos a los manteamientos de marras y a otras muchacherías, que si ahora me han salido a las espaldas, después me saldrán a los ojos. Harto mejor haría yo, sino que soy un bárbaro, y no haré nada que bueno sea en toda mi vida; harto mejor haría yo, vuelvo a decir, en volverme a mi casa, y a mi mujer, y a mis hijos, y sustentarla y criarlos con lo que Dios fue servido de darme, y no andarme tras vuesa merced por caminos sin camino y por sendas y carreras que no las tienen, bebiendo mal y comiendo peor. Pues, ;tomadme el dormir! Contad, hermano escudero, siete pies de tierra, y si quisiéredes más, tomad otros tantos, que en vuestra mano está escudillar, y tendeos a todo vuestro buen talante; que quemado vea yo y hecho polvos al primero que dio puntada en la andante caballería, o, a lo menos, al primero que quiso ser escudero de tales tontos como debieron ser todos los caballeros andantes pasados. De los presentes no digo nada, que, por ser vuestra merced uno dellos, los tengo respeto, y porque sé que sabe vuesa merced un punto más que el diablo en cuanto habla y en cuanto piensa" (II, XXVIII).

Hacia el fin de la novela don Quijote acepta la derrota tramposa que le infiere uno de sus falsos enemigos, el bachiller Sansón Carrasco disfrazado, y se dispone a cumplir la promesa de abandonar las caballerías por un año que le ha hecho a su opositor antes del asalto. De manera que su retirada, que se viene preparando desde antes de esta batalla fingida, se incorpora a la acción narrada como la consecuencia de una supuesta aventura. Don Quijote interpreta su desistimiento y fin como el resultado de una falta suya de prudencia. Dice: "Debiera pensar que al poderoso grandor del caballo del de la Blanca Luna no podía resistir la flaqueza de Rocinante. Atrevíme, en fin; hice lo que pude; derribáronme, y aunque perdí la honra, no perdí, ni puedo perder, la virtud de cumplir mi palabra. Cuando era caballero andante, atrevido y valiente, con mis obras y con mis manos acreditaba mis hechos; y agora, cuando soy escudero pedestre, acreditaré mis palabras 
cumpliendo la que di de mi promesa. Camina, pues, amigo Sancho, y vamos a tener en nuestra tierra el año de noviciado" (II, LXVI).

La verdad de las relaciones entre los protagonistas es que, acabadas las aventuras, don Quijote ya no necesita escudero y así es que comienza a abandonar al compañero aún antes de anunciarle que ambos han de devolverse a sus casas y poner fin a la existencia hasta allí compartida. Comentando la bajada a la cueva de Montesinos, los antiguos aventureros se hablan como sigue. Sancho dice: "En mala coyuntura y en peor sazón y en aciago día bajó vuestra merced, caro patrón mío, al otro mundo, y en mal punto se encontró con el señor Montesinos, que tal nos le ha vuelto. Bien se estaba vuestra merced acá arriba con su entero juicio, tal cual Dios se le había dado, hablando sentencias y dando consejos a cada paso, y no agora, contando los mayores disparates que pueden imaginarse. - Como te conozco, Sancho, respondió don Quijote, no hago caso de tus palabras. -Ni yo tampoco de las de vuestra merced, replicó Sancho, siquiera me hiera, siquiera me mate por las que le he dicho, o por las que le pienso decir si en las suyas no se corrige y enmienda" (II, XXIII).

Don Quijote solo piensa en sí mismo, en su muerte próxima, en volver a su casa, a su pueblo, en arreglar sus asuntos. Aunque para conseguir escudero aducía razones para convencer a Sancho, hasta llevarlo consigo, ahora decide desistir de la vida que han llevado juntos sin considerar, ni por un momento, al compañero. Sancho puede llorar y rogar, tratando de prolongar, tal vez como pastores, la vida novelesca. Don Quijote no le presta atención, concentrado en sí mismo, indiferente. Se ha retirado interiormente del compañerismo y la intimidad con Sancho, lo ha desertado.

Conocerse unos a otros termina, en este relato genialmente concebido por Cervantes, en aquella forma tan frecuente de intimidad que consiste en que los íntimos ya no pueden hablar entre sí porque, por indiferencia y cansancio del hábito, no se escuchan uno a otro y ya no tienen inconveniente en declarar que no creen nada de lo que el interlocutor dice y están, además, decididos de antemano a no hacer caso de lo que el otro pudiera hablarles. "Como te conozco no hago caso de tus palabras". "Ni yo tampoco de las de vuestra merced". Esta culminación fatigada de la intimidad no significa que las personas se hayan dejado de querer y de reconocer mutuamente; sólo quiere decir que la conversación ya no les revela nada acerca del interlocutor que el que escucha no tenga ya averiguado desde antes. Se comunicarán en adelante sólo noticias o lo archisabido y tenderán, por eso, a dejar de hablarse y a entenderse tácitamente, lo cual es muy diferente de dirigirse al otro con el fin de conocerse y de saber. De modo 
que, así como la novela de Cervantes desemboca en la desilusión y muerte del hombre de acción que había querido enderezar entuertos, su autor tal vez quiso mostrar además, por otro costado, que el progreso del conocimiento de los otros también puede acabar en un resultado más melancólico que estimulante. ¿Por qué el conocimiento habría de salir mejor parado que la acción? 